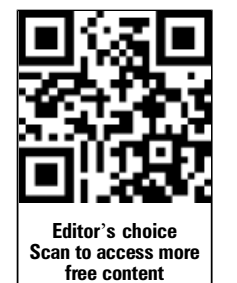

- Additional material is published online only. To view these files please visit the journal online (http://dx.doi. org/10.1136/bjsports-2013092313).

For numbered affiliations see end of article.

Correspondence to: Dr Paul McCrory, The Florey Institute of Neuroscience and Mental Health, Heidelberg, VIC 3084, Australia; paulmccr@bigpond.net.au

Received 8 February 2013 Accepted 8 February 2013

To cite: $\mathrm{McC}$ rory $\mathrm{P}$ Meeuwisse WH, Aubry M, et al. Br J Sports Med 2013:47:250-258.

\title{
Consensus statement on concussion in sport: the 4th International Conference on Concussion in Sport held in Zurich, November 2012
}

\author{
Paul McCrory, ${ }^{1}$ Willem H Meeuwisse, ${ }^{2,3}$ Mark Aubry, ${ }^{4,5,6}$ Bob Cantu, ${ }^{7,8}$ \\ Jiři Dvořák, ${ }^{9,10,11}$ Ruben J Echemendia, ${ }^{12,13}$ Lars Engebretsen, ${ }^{14,15,16}$ \\ Karen Johnston, ${ }^{17,18}$ Jeffrey S Kutcher, ${ }^{19}$ Martin Raftery, ${ }^{20}$ Allen Sills, ${ }^{21}$ \\ Brian W Benson, ${ }^{22,23,24}$ Gavin A Davis, ${ }^{25}$ Richard G Ellenbogen, ${ }^{26,27}$ \\ Kevin Guskiewicz, ${ }^{28}$ Stanley A Herring, ${ }^{29,30}$ Grant L Iverson, ${ }^{31}$ Barry D Jordan, ${ }^{32,33,34}$ \\ James Kissick, ${ }^{6,35,36,37}$ Michael McCrea, ${ }^{38}$ Andrew S Mclntosh, 39,40,41 \\ David Maddocks, ${ }^{42}$ Michael Makdissi, ${ }^{43,44}$ Laura Purcell, ${ }^{45,46}$ Margot Putukian, ${ }^{47,48}$ \\ Kathryn Schneider, ${ }^{49}$ Charles H Tator, ${ }^{50,51,52,53}$ Michael Turner $^{54}$
}

\section{PREAMBLE}

This paper is a revision and update of the recommendations developed following the 1st (Vienna 2001), 2nd (Prague 2004) and 3rd (Zurich 2008) International Consensus Conferences on Concussion in Sport and is based on the deliberations at the 4th International Conference on Concussion in Sport held in Zurich, November 2012. ${ }^{1-3}$

The new 2012 Zurich Consensus statement is designed to build on the principles outlined in the previous documents and to develop further conceptual understanding of this problem using a formal consensus-based approach. A detailed description of the consensus process is outlined at the end of this document under the Background section. This document is developed primarily for use by physicians and healthcare professionals who are involved in the care of injured athletes, whether at the recreational, elite or professional level.

While agreement exists pertaining to principal messages conveyed within this document, the authors acknowledge that the science of concussion is evolving, and therefore management and return to play (RTP) decisions remain in the realm of clinical judgement on an individualised basis. Readers are encouraged to copy and distribute freely the Zurich Consensus document, the Concussion Recognition Tool (CRT), the Sports Concussion Assessment Tool V.3 (SCAT3) and/or the Child SCAT3 card and none are subject to any restrictions, provided they are not altered in any way or converted to a digital format. The authors request that the document and/or the accompanying tools be distributed in their full and complete format.

This consensus paper is broken into a number of sections

1. A summary of concussion and its management, with updates from the previous meetings;

2. Background information about the consensus meeting process;

3. A summary of the specific consensus questions discussed at this meeting;

4. The Consensus paper should be read in conjunction with the SCAT3 assessment tool, the Child SCAT3 and the CRT (designed for lay use).

\section{SECTION 1: SPORT CONCUSSION AND ITS MANAGEMENT}

The Zurich 2012 document examines the sport concussion and management issues raised in the previous Vienna 2001, Prague 2004 and Zurich 2008 documents and applies the consensus questions from section 3 to these areas. ${ }^{1-3}$

\section{Definition of concussion}

A panel discussion regarding the definition of concussion and its separation from mild traumatic brain injury (mTBI) was held. There was acknowledgement by the Concussion in Sport Group (CISG) that although the terms mTBI and concussion are often used interchangeably in the sporting context and particularly in the US literature, others use the term to refer to different injury constructs. Concussion is the historical term representing lowvelocity injuries that cause brain 'shaking' resulting in clinical symptoms and that are not necessarily related to a pathological injury. Concussion is a subset of TBI and will be the term used in this document. It was also noted that the term commotio cerebri is often used in European and other countries. Minor revisions were made to the definition of concussion, which is defined as follows:

\footnotetext{
Concussion is a brain injury and is defined as a complex pathophysiological process affecting the brain, induced by biomechanical forces. Several common features that incorporate clinical, pathologic and biomechanical injury constructs that may be utilised in defining the nature of a concussive head injury include:
}

1. Concussion may be caused either by a direct blow to the head, face, neck or elsewhere on the body with an 'impulsive' force transmitted to the head.

2. Concussion typically results in the rapid onset of short-lived impairment of neurological function that resolves spontaneously. However, in some cases, symptoms and signs may evolve over a number of minutes to hours.

3. Concussion may result in neuropathological changes, but the acute clinical symptoms 
largely reflect a functional disturbance rather than a structural injury and, as such, no abnormality is seen on standard structural neuroimaging studies.

4. Concussion results in a graded set of clinical symptoms that may or may not involve loss of consciousness. Resolution of the clinical and cognitive symptoms typically follows a sequential course. However, it is important to note that in some cases symptoms may be prolonged.

\section{Recovery of concussion}

The majority (80-90\%) of concussions resolve in a short (710 day) period, although the recovery time frame may be longer in children and adolescents. ${ }^{2}$

\section{Symptoms and signs of acute concussion}

The diagnosis of acute concussion usually involves the assessment of a range of domains including clinical symptoms, physical signs, cognitive impairment, neurobehavioural features and sleep disturbance. Furthermore, a detailed concussion history is an important part of the evaluation both in the injured athlete and when conducting a preparticipation examination. The detailed clinical assessment of concussion is outlined in the SCAT3 and Child SCAT3 forms, which are given in the appendix to this document.

The suspected diagnosis of concussion can include one or more of the following clinical domains:

1. Symptoms - somatic (eg, headache), cognitive (eg, feeling like in a fog) and/or emotional symptoms (eg, lability);

2. Physical signs (eg, loss of consciousness (LOC), amnesia);

3. Behavioural changes (eg, irritability);

4. Cognitive impairment (eg, slowed reaction times);

5. Sleep disturbance (eg, insomnia).

If any one or more of these components are present, a concussion should be suspected and the appropriate management strategy instituted.

\section{On-field or sideline evaluation of acute concussion}

When a player shows ANY features of a concussion:

A. The player should be evaluated by a physician or other licensed healthcare provider onsite using standard emergency management principles and particular attention should be given to excluding a cervical spine injury.

B. The appropriate disposition of the player must be determined by the treating healthcare provider in a timely manner. If no healthcare provider is available, the player should be safely removed from practice or play and urgent referral to a physician arranged.

C. Once the first aid issues are addressed, an assessment of the concussive injury should be made using the SCAT3 or other sideline assessment tools.

D. The player should not be left alone following the injury and serial monitoring for deterioration is essential over the initial few hours following injury.

E. A player with diagnosed concussion should not be allowed to RTP on the day of injury.

Sufficient time for assessment and adequate facilities should be provided for the appropriate medical assessment both on and off the field for all injured athletes. In some sports, this may require rule change to allow an appropriate off-field medical assessment to occur without affecting the flow of the game or unduly penalising the injured player's team. The final determination regarding concussion diagnosis and/or fitness to play is a medical decision based on clinical judgement.
Sideline evaluation of cognitive function is an essential component in the assessment of this injury. Brief neuropsychological test batteries that assess attention and memory function have been shown to be practical and effective. Such tests include the SCAT3, which incorporates the Maddocks' questions ${ }^{45}$ and the Standardized Assessment of Concussion (SAC) ${ }^{6-8}$ It is worth noting that standard orientation questions (eg, time, place and person) have been shown to be unreliable in the sporting situation when compared with memory assessment. ${ }^{5} 9$ It is recognised, however, that abbreviated testing paradigms are designed for rapid concussion screening on the sidelines and are not meant to replace comprehensive neuropsychological testing which should ideally be performed by trained neuropsychologists who are sensitive to subtle deficits that may exist beyond the acute episode; nor should they be used as a stand-alone tool for the ongoing management of sports concussions.

It should also be recognised that the appearance of symptoms or cognitive deficit might be delayed several hours following a concussive episode and that concussion should be seen as an evolving injury in the acute stage.

\section{Evaluation in the emergency room or office by medical personnel}

An athlete with concussion may be evaluated in the emergency room or doctor's office as a point of first contact following injury or may have been referred from another care provider. In addition to the points outlined above, the key features of this examination should encompass:

A. A medical assessment including a comprehensive history and detailed neurological examination including a thorough assessment of mental status, cognitive functioning, gait and balance.

B. A determination of the clinical status of the patient, including whether there has been improvement or deterioration since the time of injury. This may involve seeking additional information from parents, coaches, teammates and eyewitnesses to the injury.

C. A determination of the need for emergent neuroimaging in order to exclude a more severe brain injury involving a structural abnormality.

In large part, these points above are included in the SCAT3 assessment.

\section{Concussion investigations}

A range of additional investigations may be utilised to assist in the diagnosis and/or exclusion of injury. Conventional structural neuroimaging is typically normal in concussive injury. Given that caveat, the following suggestions are made: Brain CT (or where available an MR brain scan) contributes little to concussion evaluation but should be employed whenever suspicion of an intracerebral or structural lesion (eg, skull fracture) exists. Examples of such situations may include prolonged disturbance of the conscious state, focal neurological deficit or worsening symptoms.

Other imaging modalities such as fMRI demonstrate activation patterns that correlate with symptom severity and recovery in concussion. ${ }^{10-14}$ Although not part of routine assessment at the present time, they nevertheless provide additional insight to pathophysiological mechanisms. Alternative imaging technologies (eg, positron emission tomography, diffusion tensor imaging, magnetic resonance spectroscopy, functional connectivity), while demonstrating some compelling findings, are still at early stages of development and cannot be recommended other than in a research setting. 
Published studies, using both sophisticated force plate technology, as well as those using less sophisticated clinical balance tests (eg, Balance Error Scoring System (BESS)), have identified acute postural stability deficits lasting approximately $72 \mathrm{~h}$ following sports-related concussion. It appears that postural stability testing provides a useful tool for objectively assessing the motor domain of neurological functioning, and should be considered as a reliable and valid addition to the assessment of athletes suffering from concussion, particularly where the symptoms or signs indicate a balance component. ${ }^{15-21}$

The significance of Apolipoprotein (Apo) E4, ApoE promoter gene, Tau polymerase and other genetic markers in the management of sports concussion risk or injury outcome is unclear at this time. ${ }^{22} 23$ Evidence from human and animal studies in more severe traumatic brain injury demonstrates induction of a variety of genetic and cytokine factors such as: insulin-like growth factor 1 (IGF-1), IGF binding protein 2, Fibroblast growth factor, $\mathrm{Cu}-\mathrm{Zn}$ superoxide dismutase, superoxide dismutase 1 (SOD-1), nerve growth factor, glial fibrillar acidic protein (GFAP) and S-100. How such factors are affected in sporting concussion is not known at this stage. ${ }^{24-31}$ In addition, biochemical serum and cerebral spinal fluid biomarkers of brain injury (including S-100, neuron-specific enolase (NSE), myelin basic protein (MBP), GFAP, tau, etc) have been proposed as a means by which cellular damage may be detected if present. ${ }^{32-38}$ There is currently insufficient evidence, however, to justify the routine use of these biomarkers clinically.

Different electrophysiological recording techniques (eg, evoked response potential (ERP), cortical magnetic stimulation and electroencephalography) have demonstrated reproducible abnormalities in the postconcussive state; however, not all studies reliably differentiated concussed athletes from controls. ${ }^{39-45}$ The clinical significance of these changes remains to be established.

\section{Neuropsychological assessment}

The application of neuropsychological (NP) testing in concussion has been shown to be of clinical value and contributes significant information in concussion evaluation. ${ }^{46-51}$ Although cognitive recovery largely overlaps with the time course of symptom recovery in most cases, it has been demonstrated that cognitive recovery may occasionally precede or more commonly follow clinical symptom resolution, suggesting that the assessment of cognitive function should be an important component in the overall assessment of concussion and, in particular, any RTP protocol. ${ }^{52} 53$ It must be emphasised, however, that NP assessment should not be the sole basis of management decisions. Rather, it should be seen as an aid to the clinical decisionmaking process in conjunction with a range of assessments of different clinical domains and investigational results.

It is recommended that all athletes should have a clinical neurological assessment (including assessment of their cognitive function) as part of their overall management. This will normally be performed by the treating physician often in conjunction with computerised neuropsychological screening tools.

Formal NP testing is not required for all athletes; however, when this is considered necessary, it should ideally be performed by a trained neuropsychologist. Although neuropsychologists are in the best position to interpret NP tests by virtue of their background and training, the ultimate RTP decision should remain a medical one in which a multidisciplinary approach, when possible, has been taken. In the absence of NP and other (eg, formal balance assessment) testing, a more conservative RTP approach may be appropriate.
NP testing may be used to assist RTP decisions and is typically performed when an athlete is clinically asymptomatic; however, NP assessment may add important information in the early stages following injury. ${ }^{54} 55$ There may be particular situations where testing is performed early to assist in determining aspects of management, for example, return to school in a paediatric athlete. This will normally be best determined in consultation with a trained neuropsychologist. ${ }^{56} 57$

Baseline NP testing was considered by the panel and was not felt to be required as a mandatory aspect of every assessment; however, it may be helpful to add useful information to the overall interpretation of these tests. It also provides an additional educative opportunity for the physician to discuss the significance of this injury with the athlete. At present, there is insufficient evidence to recommend the widespread routine use of baseline neuropsychological testing.

\section{Concussion management}

The cornerstone of concussion management is physical and cognitive rest until the acute symptoms resolve and then a graded programme of exertion prior to medical clearance and RTP. The current published evidence evaluating the effect of rest following a sports-related concussion is sparse. An initial period of rest in the acute symptomatic period following injury (24-48 h) may be of benefit. Further research to evaluate the long-term outcome of rest, and the optimal amount and type of rest, is needed. In the absence of evidence-based recommendations, a sensible approach involves the gradual return to school and social activities (prior to contact sports) in a manner that does not result in a significant exacerbation of symptoms.

Low-level exercise for those who are slow to recover may be of benefit, although the optimal timing following injury for initiation of this treatment is currently unknown.

As described above, the majority of injuries will recover spontaneously over several days. In these situations, it is expected that an athlete will proceed progressively through a stepwise RTP strategy. ${ }^{58}$

\section{Graduated RTP protocol}

RTP protocol following a concussion follows a stepwise process as outlined in table 1.

With this stepwise progression, the athlete should continue to proceed to the next level if asymptomatic at the current level. Generally, each step should take $24 \mathrm{~h}$ so that an athlete would take approximately 1 week to proceed through the full rehabilitation protocol once they are asymptomatic at rest and with provocative exercise. If any postconcussion symptoms occur while in the stepwise programme, then the patient should drop back to the previous asymptomatic level and try to progress again after a further $24 \mathrm{~h}$ period of rest has passed.

\section{Same day RTP}

It was unanimously agreed that no RTP on the day of concussive injury should occur. There are data demonstrating that at the collegiate and high school levels, athletes allowed to RTP on the same day may demonstrate NP deficits postinjury that may not be evident on the sidelines and are more likely to have delayed onset of symptoms. ${ }^{59-65}$

\section{'Difficult' or persistently symptomatic concussion patient}

Persistent symptoms (>10 days) are generally reported in $10-15 \%$ of concussions. In general, symptoms are not specific to concussion and it is important to consider other pathologies. 
Table 1 Graduated return to play protocol

\begin{tabular}{|c|c|c|}
\hline $\begin{array}{l}\text { Rehabilitation } \\
\text { stage }\end{array}$ & $\begin{array}{l}\text { Functional exercise at each } \\
\text { stage of rehabilitation }\end{array}$ & $\begin{array}{l}\text { Objective of each } \\
\text { stage }\end{array}$ \\
\hline 1. No activity & $\begin{array}{l}\text { Symptom limited physical and } \\
\text { cognitive rest }\end{array}$ & Recovery \\
\hline $\begin{array}{l}\text { 2. Light aerobic } \\
\text { exercise }\end{array}$ & $\begin{array}{l}\text { Walking, swimming or } \\
\text { stationary cycling keeping } \\
\text { intensity }<70 \% \text { maximum } \\
\text { permitted heart rate } \\
\text { No resistance training }\end{array}$ & Increase HR \\
\hline $\begin{array}{l}\text { 3. Sport-specific } \\
\text { exercise }\end{array}$ & $\begin{array}{l}\text { Skating drills in ice hockey, } \\
\text { running drills in soccer. No } \\
\text { head impact activities }\end{array}$ & Add movement \\
\hline $\begin{array}{l}\text { 4. Non-contact } \\
\text { training drills }\end{array}$ & $\begin{array}{l}\text { Progression to more complex } \\
\text { training drills, eg, passing drills } \\
\text { in football and ice hockey } \\
\text { May start progressive } \\
\text { resistance training }\end{array}$ & $\begin{array}{l}\text { Exercise, coordination } \\
\text { and cognitive load }\end{array}$ \\
\hline $\begin{array}{l}\text { 5. Full-contact } \\
\text { practice }\end{array}$ & $\begin{array}{l}\text { Following medical clearance } \\
\text { participate in normal training } \\
\text { activities }\end{array}$ & $\begin{array}{l}\text { Restore confidence and } \\
\text { assess functional skills } \\
\text { by coaching staff }\end{array}$ \\
\hline 6. Return to play & Normal game play & \\
\hline
\end{tabular}

Cases of concussion in sport where clinical recovery falls outside the expected window (ie, 10 days) should be managed in a multidisciplinary manner by healthcare providers with experience in sports-related concussion.

\section{Psychological management and mental health issues}

Psychological approaches may have potential application in this injury, particularly with the modifiers listed below. ${ }^{66} 67$ Physicians are also encouraged to evaluate the concussed athlete for affective symptoms such as depression and anxiety as these symptoms are common in all forms of traumatic brain injury. ${ }^{58}$

\section{Role of pharmacological therapy}

Pharmacological therapy in sports concussion may be applied in two distinct situations. The first of these situations is the management of specific and/or prolonged symptoms (eg, sleep disturbance, anxiety, etc). The second situation is where drug therapy is used to modify the underlying pathophysiology of the condition with the aim of shortening the duration of the concussion symptoms. ${ }^{68}$ In broad terms, this approach to management should be only considered by clinicians experienced in concussion management.

An important consideration in RTP is that concussed athletes should not only be symptom-free, but also they should not be taking any pharmacological agents/medications that may mask or modify the symptoms of concussion. Where antidepressant therapy may be commenced during the management of a concussion, the decision to RTP while still on such medication must be considered carefully by the treating clinician.

\section{Role of preparticipation concussion evaluation}

Recognising the importance of a concussion history, and appreciating the fact that many athletes will not recognise all the concussions they may have suffered in the past, a detailed concussion history is of value. ${ }^{69-72}$ Such a history may preidentify athletes who fit into a high-risk category and provides an opportunity for the healthcare provider to educate the athlete in regard to the significance of concussive injury. A structured concussion history should include specific questions as to previous symptoms of a concussion and length of recovery; not just the perceived number of past concussions. It is also worth noting that dependence on the recall of concussive injuries by teammates or coaches has been demonstrated to be unreliable. ${ }^{69}$ The clinical history should also include information about all previous head, face or cervical spine injuries as these may also have clinical relevance. It is worth emphasising that in the setting of maxillofacial and cervical spine injuries, coexistent concussive injuries may be missed unless specifically assessed. Questions pertaining to disproportionate impact versus symptom severity matching may alert the clinician to a progressively increasing vulnerability to injury. As part of the clinical history, it is advised that details regarding protective equipment employed at the time of injury be sought, both for recent and remote injuries.

There is an additional and often unrecognised benefit of the preparticipation physical examination insofar as the evaluation allows for an educative opportunity with the player concerned as well as consideration of modification of playing behaviour if required.

\section{Modifying factors in concussion management}

A range of 'modifying' factors may influence the investigation and management of concussion and, in some cases, may predict the potential for prolonged or persistent symptoms. However, in some cases, the evidence for their efficacy is limited. These modifiers would be important to consider in a detailed concussion history and are outlined in table 2 .

\section{Female gender}

The role of female gender as a possible modifier in the management of concussion was discussed at length by the panel. There was no unanimous agreement that the current published research evidence is conclusive enough for this to be included as a modifying factor, although it was accepted that gender may be a risk factor for injury and/or influence injury severity. ${ }^{73-75}$

\section{Significance of LOC}

In the overall management of moderate-to-severe traumatic brain injury, duration of LOC is an acknowledged predictor of

Table 2 Concussion modifiers

\begin{tabular}{|c|c|}
\hline Factors & Modifier \\
\hline Symptoms & $\begin{array}{l}\text { Number } \\
\text { Duration (>10 days) } \\
\text { Severity }\end{array}$ \\
\hline Signs & $\begin{array}{l}\text { Prolonged loss of consciousness (LOC) (>1 min), } \\
\text { Amnesia }\end{array}$ \\
\hline Sequelae & Concussive convulsions \\
\hline Temporal & $\begin{array}{l}\text { Frequency-repeated concussions over time } \\
\text { Timing-injuries close together in time } \\
\text { 'Recency'-recent concussion or traumatic brain } \\
\text { injury (TBI) }\end{array}$ \\
\hline Threshold & $\begin{array}{l}\text { Repeated concussions occurring with progressively } \\
\text { less impact force or slower recovery after each } \\
\text { successive concussion }\end{array}$ \\
\hline Age & Child and adolescent ( $<18$ years old) \\
\hline $\begin{array}{l}\text { Comorbidities and } \\
\text { premorbidities }\end{array}$ & $\begin{array}{l}\text { Migraine, depression or other mental health } \\
\text { disorders, attention deficit hyperactivity disorder } \\
\text { (ADHD), learning disabilities (LD), sleep disorders }\end{array}$ \\
\hline Medication & Psychoactive drugs, anticoagulants \\
\hline Behaviour & Dangerous style of play \\
\hline Sport & $\begin{array}{l}\text { High-risk activity, contact and collision sport, high } \\
\text { sporting level }\end{array}$ \\
\hline
\end{tabular}


outcome. ${ }^{76}$ Although published findings in concussion describe LOC associated with specific, early cognitive deficits, it has not been noted as a measure of injury severity. ${ }^{77} 78$ Consensus discussion determined that prolonged ( $>1$ min duration) LOC would be considered as a factor that may modify management.

\section{Significance of amnesia and other symptoms}

There is renewed interest in the role of post-traumatic amnesia and its role as a surrogate measure of injury severity. ${ }^{64} 7980$ Published evidence suggests that the nature, burden and duration of the clinical postconcussive symptoms may be more important than the presence or duration of amnesia alone. ${ }^{778182}$ Further, it must be noted that retrograde amnesia varies with the time of measurement postinjury and hence is poorly reflective of injury severity. ${ }^{83} 84$

\section{Motor and convulsive phenomena}

A variety of immediate motor phenomena (eg, tonic posturing) or convulsive movements may accompany a concussion. Although dramatic, these clinical features are generally benign and require no specific management beyond the standard treatment of the underlying concussive injury. ${ }^{85} 86$

\section{Depression}

Mental health issues (such as depression) have been reported as a consequence of all levels of traumatic brain injury including sports-related concussion. Neuroimaging studies using fMRI suggest that a depressed mood following concussion may reflect an underlying pathophysiological abnormality consistent with a limbic-frontal model of depression. ${ }^{34}{ }^{87-97}$ Although such mental health issues may be multifactorial in nature, it is recommended that the treating physician consider these issues in the management of concussed patients.

\section{SPECIAL POPULATIONS \\ Child and adolescent athlete}

The evaluation and management recommendations contained herein can be applied to children and adolescents down to the age of 13 years. Below that age, children report concussion symptoms different from adults and would require age-appropriate symptom checklists as a component of assessment. An additional consideration in assessing the child or adolescent athlete with a concussion is that the clinical evaluation by the healthcare professional may need to include both patient and parent input, and possibly teacher and school input when appropriate. ${ }^{98-104}$ A child SCAT3 has been developed to assess concussion (see appendix) for individuals aged 5-12 years.

The decision to use NP testing is broadly the same as the adult assessment paradigm, although there are some differences. The timing of testing may differ in order to assist planning in school and home management. If cognitive testing is performed, then it must be developmentally sensitive until late teen years due to the ongoing cognitive maturation that occurs during this period, which in turn limits the utility of comparison to either the person's own baseline performance or to population norms. ${ }^{20}$ In this age group, it is more important to consider the use of trained paediatric neuropsychologists to interpret assessment data, particularly in children with learning disorders and/or ADHD who may need more sophisticated assessment strategies. ${ }^{56} 5798$

It was agreed by the panel that no return to sport or activity should occur before the child/adolescent athlete has managed to return to school successfully. In addition, the concept of 'cognitive rest' was highlighted with special reference to a child's need to limit exertion with activities of daily living that may exacerbate symptoms. School attendance and activities may also need to be modified to avoid provocation of symptoms. Children should not be returned to sport until clinically completely symptom-free, which may require a longer time frame than for adults.

Because of the different physiological response and longer recovery after concussion and specific risks (eg, diffuse cerebral swelling) related to head impact during childhood and adolescence, a more conservative RTP approach is recommended. It is appropriate to extend the amount of time of asymptomatic rest and/or the length of the graded exertion in children and adolescents. It is not appropriate for a child or adolescent athlete with concussion to RTP on the same day as the injury, regardless of the level of athletic performance. Concussion modifiers apply even more to this population than adults and may mandate more cautious RTP advice.

\section{Elite versus non-elite athletes}

All athletes, regardless of the level of participation, should be managed using the same treatment and RTP paradigm. The available resources and expertise in concussion evaluation are of more importance in determining management than a separation between elite and non-elite athlete management. Although formal NP testing may be beyond the resources of many sports or individuals, it is recommended that, in all organised high-risk sports, consideration be given to having this cognitive evaluation, regardless of the age or level of performance.

\section{Chronic traumatic encephalopathy}

Clinicians need to be mindful of the potential for long-term problems in the management of all athletes. However, it was agreed that chronic traumatic encephalopathy (CTE) represents a distinct tauopathy with an unknown incidence in athletic populations. It was further agreed that a cause and effect relationship has not as yet been demonstrated between CTE and concussions or exposure to contact sports. ${ }^{105-114}$ At present, the interpretation of causation in the modern CTE case studies should proceed cautiously. It was also recognised that it is important to address the fears of parents/athletes from media pressure related to the possibility of CTE.

\section{INJURY PREVENTION}

\section{Protective equipment-mouthguards and helmets}

There is no good clinical evidence that currently available protective equipment will prevent concussion, although mouthguards have a definite role in preventing dental and orofacial injury. Biomechanical studies have shown a reduction in impact forces to the brain with the use of head gear and helmets, but these findings have not been translated to show a reduction in concussion incidence. For skiing and snowboarding, there are a number of studies to suggest that helmets provide protection against head and facial injury and hence should be recommended for participants in alpine sports. ${ }^{115-118}$ In specific sports such as cycling, motor and equestrian sports, protective helmets may prevent other forms of head injury (eg, skull fracture) that are related to falling on hard surfaces and may be an important injury prevention issue for those sports. ${ }^{118-130}$

\section{Rule change}

Consideration of rule changes to reduce the head injury incidence or severity may be appropriate where a clear-cut mechanism is implicated in a particular sport. An example of this is in football (soccer) where research studies demonstrated that upper limb to head contact in heading contests accounted for approximately $50 \%$ of concussions. ${ }^{131}$ As noted earlier, rule changes 
may also be needed in some sports to allow an effective off-field medical assessment to occur without compromising the athlete's welfare, affecting the flow of the game or unduly penalising the player's team. It is important to note that rule enforcement may be a critical aspect of modifying injury risk in these settings, and referees play an important role in this regard.

\section{Risk compensation}

An important consideration in the use of protective equipment is the concept of risk compensation. ${ }^{132}$ This is where the use of protective equipment results in behavioural change such as the adoption of more dangerous playing techniques, which can result in a paradoxical increase in injury rates. The degree to which this phenomenon occurs is discussed in more detail in the review published in this supplement of the journal. This may be a matter of particular concern in child and adolescent athletes where the head injury rates are often higher than in adult athletes. ${ }^{133-135}$

\section{Aggression versus violence in sport}

The competitive/aggressive nature of sport that makes it fun to play and watch should not be discouraged. However, sporting organisations should be encouraged to address violence that may increase concussion risk. ${ }^{136}{ }^{137}$ Fair play and respect should be supported as key elements of sport.

\section{Knowledge transfer}

As the ability to treat or reduce the effects of concussive injury after the event is minimal, education of athletes, colleagues and the general public is a mainstay of progress in this field. Athletes, referees, administrators, parents, coaches and healthcare providers must be educated regarding the detection of concussion, its clinical features, assessment techniques and principles of safe RTP. Methods to improve education including web-based resources, educational videos and international outreach programmes are important in delivering the message. In addition, concussion working groups, plus the support and endorsement of enlightened sport groups such as Fédération Internationale de Football Association (FIFA), International Olympic Commission (IOC), International Rugby Board (IRB) and International Ice Hockey Federation (IIHF), who initiated this endeavour, have enormous value and must be pursued vigorously. Fair play and respect for opponents are ethical values that should be encouraged in all sports and sporting associations. Similarly, coaches, parents and managers play an important part in ensuring that these values are implemented on the field of play. ${ }^{58} 138-150$

\section{SECTION 2: STATEMENT ON BACKGROUND TO THE CONSENSUS PROCESS}

In November 2001, the 1st International Conference on Concussion in Sport was held in Vienna, Austria. This meeting was organised by the IIHF in partnership with FIFA and the Medical Commission of the IOC. As part of the resulting mandate for the future, the need for leadership and future updates was identified. The 2nd International Conference on Concussion in Sport was organised by the same group with the additional involvement of the IRB and was held in Prague, the Czech Republic, in November 2004. The original aims of the symposia were to provide recommendations for the improvement of safety and health of athletes who suffer concussive injuries in ice hockey, rugby, football (soccer) as well as other sports. To this end, a range of experts were invited to both meetings to address specific issues of epidemiology, basic and clinical science, injury grading systems, cognitive assessment, new research methods, protective equipment, management, prevention and long-term outcome. ${ }^{12}$

The 3rd International Conference on Concussion in Sport was held in Zurich, Switzerland on 29/30 October 2008 and was designed as a formal consensus meeting following the organisational guidelines set forth by the US National Institutes of Health. (Details of the consensus methodology can be obtained at: http://consensus.nih.gov/ABOUTCDP.htm.) The basic principles governing the conduct of a consensus development conference are summarised below:

1. A broad-based non-government, non-advocacy panel was assembled to give balanced, objective and knowledgeable attention to the topic. Panel members excluded anyone with scientific or commercial conflicts of interest and included researchers in clinical medicine, sports medicine, neuroscience, neuroimaging, athletic training and sports science.

2. These experts presented data in a public session, followed by inquiry and discussion. The panel then met in an executive session to prepare the consensus statement.

3. A number of specific questions were prepared and posed in advance to define the scope and guide the direction of the conference. The principal task of the panel was to elucidate responses to these questions. These questions are outlined below.

4. A systematic literature review was prepared and circulated in advance for use by the panel in addressing the conference questions.

5. The consensus statement is intended to serve as the scientific record of the conference.

6. The consensus statement will be widely disseminated to achieve maximum impact on both current healthcare practice and future medical research.

The panel chairperson (WM) did not identify with any advocacy position. The chairperson was responsible for directing the consensus session and guiding the panel's deliberations. Panellists were drawn from clinical practice, academics and research in the field of sports-related concussion. They do not represent organisations per se, but were selected for their expertise, experience and understanding of this field.

The 4th International Conference on Concussion in Sport was held in Zurich, Switzerland on 1-3 November 2012 and followed the same outline as for the third meeting. All speakers, consensus panel members and abstract authors were required to sign an ICMJE Form for Disclosure of Potential Conflicts of Interest. Detailed information related to each author's affiliations and conflicts of interests will be made publicly available on the CISG website and published with the BJSM supplement.

\section{Medical legal considerations}

This consensus document reflects the current state of knowledge and will need to be modified according to the development of new knowledge. It provides an overview of issues that may be of importance to healthcare providers involved in the management of sports-related concussion. It is not intended as a standard of care, and should not be interpreted as such. This document is only a guide, and is of a general nature, consistent with the reasonable practice of a healthcare professional. Individual treatment will depend on the facts and circumstances specific to each individual case.

It is intended that this document will be formally reviewed and updated prior to 1 December 2016. 


\section{SECTION 3: ZURICH 2012 CONSENSUS QUESTIONS}

Note that each question is the subject of a separate systematic review that is published in the BJSM (2013:47:5). As such, all citations and details of each topic will be covered in those reviews.

\section{When you assess an athlete acutely and they do not have a concussion, what is it? Is a cognitive injury the key component of concussion in making a diagnosis?}

The consensus panel agreed that concussion is an evolving injury in the acute phase with rapidly changing clinical signs and symptoms, which may reflect the underlying physiological injury in the brain. Concussion is considered to be among the most complex injuries in sports medicine to diagnose, assess and manage. A majority of concussions in sport occur without LOC or frank neurological signs. At present, there is no perfect diagnostic test or marker that clinicians can rely on for an immediate diagnosis of concussion in the sporting environment. Because of this evolving process, it is not possible to rule out concussion when an injury event occurs associated with a transient neurological symptom. All such cases should be removed from the playing field and assessed for concussion by the treating physician or healthcare provider as discussed below. It was recognised that a cognitive deficit is not necessary for acute diagnosis as it either may not be present or detected on examination.

\section{Are the existing tools/examination sensitive and reliable enough on the day of injury to make or exclude a diagnosis of concussion?}

Concussion is a clinical diagnosis based largely on the observed injury mechanism, signs and symptoms. The vast majority of sports-related concussions (hereafter, referred to as concussion) occur without LOC or frank neurological signs. ${ }^{151-154}$ In milder forms of concussion, the athlete might be slightly confused, without clearly identifiable amnesia. In addition, most concussions cannot be identified or diagnosed by neuroimaging techniques (eg, CT or MRI). Several well-validated neuropsychological tests are appropriate for use in the assessment of acute concussion in the competitive sporting environment. These tests provide important data on symptoms and functional impairments that clinicians can incorporate into their diagnostic formulation, but should not solely be used to diagnose concussion.

\section{What is the best practice for evaluating an adult athlete with concussion on the 'field of play' in 2012?}

Recognising and evaluating concussion in the adult athlete on the field is a challenging responsibility for the healthcare provider. Performing this task is often a rapid assessment in the midst of competition with a time constraint and the athlete eager to play. A standardised objective assessment of injury, which includes excluding more serious injury, is critical in determining disposition decisions for the athlete. The on-field evaluation of sports-related concussion is often a challenge given the elusiveness and variability of presentation, difficulty in making a timely diagnosis, specificity and sensitivity of sideline assessment tools, and the reliance on symptoms. Despite these challenges, the sideline evaluation is based on recognition of injury, assessment of symptoms, cognitive and cranial nerve function, and balance. Serial assessments are often necessary. Concussion is often an evolving injury, and signs and symptoms may be delayed. Therefore, erring on the side of caution (keeping an athlete out of participation when there is any suspicion for injury) is important. An SAC is useful in the assessment of the athlete with suspected concussion but should not take the place of the clinician's judgement.

\section{How can the SCAT2 be improved?}

It was agreed that a variety of measures should be employed as part of the assessment of concussion to provide a more complete clinical profile for the concussed athlete. Important clinical information can be ascertained in a streamlined manner through the use of a multimodal instrument such as the Sport Concussion Assessment Tool (SCAT). A baseline assessment is advised wherever possible. However, it is acknowledged that further validity studies need to be performed to answer this specific issue.

A future SCAT test battery (ie, SCAT3) should include an initial assessment of injury severity using the Glasgow Coma Scale (GCS), immediately followed by observing and documenting concussion signs. Once this is complete, symptom endorsement and symptom severity, as well as neurocognitive and balance functions, should be assessed in any athlete suspected of sustaining a concussion. It is recommended that these latter steps be conducted following a minimum 15 min rest period on the sideline to avoid the influence of exertion or fatigue on the athlete's performance. Although it is noted that this time frame is an arbitrary one, the expert panel agreed nevertheless that a period of rest was important prior to assessment. Future research should consider the efficacy for inclusion of vision tests such as the King Devick Test and clinical reaction time tests. ${ }^{155}{ }^{156}$ Recent studies suggest that these may be useful additions to the sideline assessment of concussion. However, the need for additional equipment may make them impractical for sideline use.

It was further agreed that the SCAT3 would be suitable for adults and youths aged 13 and over and that a new tool (Child SCAT3) be developed for younger children.

\section{Advances in neuropsychology: are computerised tests sufficient for concussion diagnosis?}

Sports-related concussions are frequently associated with one or more symptoms, impaired balance and/or cognitive deficits. These problems can be measured using symptom scales, balance testing and neurocognitive testing. All three modalities can identify significant changes in the first few days following injury, generally with normalisation over $1-3$ weeks. The presentation of symptoms and the rate of recovery can be variable, which reinforces the value of assessing all three areas as part of a comprehensive sport concussion programme.

Neuropsychological assessment has been described by the CISG as a 'cornerstone' of concussion management. Neuropsychologists are uniquely qualified to interpret neuropsychological tests and can play an important role within the context of a multifaceted-multimodal and multidisciplinary approach to managing sports-related concussion. Concussion management programmes that use neuropsychological assessment to assist in clinical decision-making have been instituted in professional sports, colleges and high schools. Brief computerised cognitive evaluation tools are the mainstay of these assessments worldwide, given the logistical limitation in accessing trained neuropsychologists; however, it should be noted that these are not substitutes for formal neuropsychological assessment. At present, there is insufficient evidence to recommend the widespread routine use of baseline neuropsychological testing.

What evidence exists for new strategies/technologies in the diagnosis of concussion and assessment of recovery?

A number of novel technological platforms exist to assess concussion including (but not limited to) iPhone/smart phone apps, quantitative electroencephalography, robotics-sensory motor 
assessment, telemedicine, eye-tracking technology, functional imaging/advanced neuroimaging and head impact sensors. At this stage, only limited evidence exists for their role in this setting and none have been validated as diagnostic. It will be important to reconsider the role of these technologies once evidence is developed.

\section{Advances in the management of sport concussion: what is evidence for concussion therapies}

The current evidence evaluating the effect of rest and treatment following a sports-related concussion is sparse. An initial period of rest may be of benefit. However, further research to evaluate the long-term outcome of rest, and the optimal amount and type of rest, is needed. Low-level exercise for those who are slow to recover may be of benefit, although the optimal timing following injury for initiation of this treatment is currently unknown. Multimodal physiotherapy treatment for individuals with clinical evidence of cervical spine and/or vestibular dysfunction may be of benefit. There is a strong need for high-level studies evaluating the effects of a resting period, pharmacological interventions, rehabilitative techniques and exercise for individuals who have sustained a sports-related concussion.

\section{The difficult concussion patient-What is the best approach to investigation and management of persistent ( $>10$ days) postconcussive symptoms?}

Persistent symptoms ( $>10$ days) are generally reported in $10-15 \%$ of concussions. This may be higher in certain sports (eg, elite ice hockey) and populations (eg, children). In general, symptoms are not specific to concussion and it is important to consider and manage co-existent pathologies. Investigations may include formal neuropsychological testing and conventional neuroimaging to exclude structural pathology. Currently, there is insufficient evidence to recommend routine clinical use of advanced neuroimaging techniques or other investigative strategies. Cases of concussion in sport where clinical recovery falls outside the expected window (ie, 10 days) should be managed in a multidisciplinary manner by healthcare providers with experience in sports-related concussion. Important components of management after the initial period of physical and cognitive rest include associated therapies such as cognitive, vestibular, physical and psychological therapy, consideration of assessment of other causes of prolonged symptoms and consideration of commencement of a graded exercise programme at a level that does not exacerbate symptoms.

\section{Revisiting concussion modifiers: how should the evaluation and management of acute concussion differ in specific groups?}

The literature demonstrates that the number and severity of symptoms and previous concussions are associated with prolonged recovery and/or increased risk of complications. Brief LOC, duration of post-traumatic amnesia and/or impact seizures do not reliably predict outcome following concussion, although a cautious approach should be taken in an athlete with prolonged LOC (ie, >1 min). Children generally take longer to recover from concussions and assessment batteries have yet to be validated in the younger age group. Currently, there are insufficient data on the influence of genetics and gender on outcome following concussion. Several modifiers are associated with prolonged recovery or increased risk of complications following concussion and have important implications for management. Children with concussion should be managed conservatively, with the emphasis on return to learn before return to sport. In cases of concussion managed with limited resources (eg, non-elite players), a conservative approach should also be taken such that the athlete does not return to sport until fully recovered.

What are the most effective risk reduction strategies in sport concussion?-from protective equipment to policy?

No new valid evidence was provided to suggest that the use of current standard headgear in rugby, or of mouthguards in American football, can significantly reduce players' risk of concussion. No evidence was provided to suggest an association between neck strength increases and concussion risk reduction. There was evidence to suggest that eliminating body checking from Pee Wee ice hockey (ages 11-12 years) and fair-play rules in ice hockey were effective injury prevention strategies. Helmets need to be able to protect from impacts resulting in a head change in velocity of up to $10 \mathrm{~m} / \mathrm{s}$ in professional American football, and up to $7 \mathrm{~m} / \mathrm{s}$ in professional Australian football. It also appears that helmets must be capable of reducing head-resultant linear acceleration to below $50 \mathrm{~g}$ and angular acceleration components to below $1500 \mathrm{rad} / \mathrm{s}^{2}$ to optimise their effectiveness. Given that a multifactorial approach is needed for concussion prevention, well-designed and sport-specific prospective analytical studies of sufficient power are warranted for mouthguards, headgear/helmets, facial protection and neck strength. Measuring the effect of rule changes should also be addressed by future studies, not only assessing new rule changes or legislation, but also alteration or reinforcement to existing rules.

\section{What is the evidence for chronic concussion-related} changes?-behavioural, pathological and clinical outcomes It was agreed that CTE represents a distinct tauopathy with an unknown incidence in athletic populations. It was further agreed that CTE was not related to concussions alone or simply exposure to contact sports. At present, there are no published epidemiological, cohort or prospective studies relating to modern CTE. Owing to the nature of the case reports and pathological case series that have been published, it is not possible to determine the causality or risk factors with any certainty. As such, the speculation that repeated concussion or subconcussive impacts cause CTE remains unproven. The extent to which age-related changes, psychiatric or mental health illness, alcohol/ drug use or co-existing medical or dementing illnesses contribute to this process is largely unaccounted for in the published literature. At present, the interpretation of causation in the modern CTE case studies should proceed cautiously. It was also recognised that it is important to address the fears of parents/ athletes from media pressure related to the possibility of CTE.

From consensus to action-how do we optimise knowledge transfer, education and ability to influence policy?

The value of knowledge transfer (KT) as part of concussion education is increasingly becoming recognised. Target audiences benefit from specific learning strategies. Concussion tools exist, but their effectiveness and impact require further evaluation. The media is valuable in drawing attention to concussion, but efforts need to ensure that the public is aware of the right information. Social media as a concussion education tool is becoming more prominent. Implementation of KT models is one approach organisations can use to assess knowledge gaps; identify, develop and evaluate education strategies; and use the outcomes to facilitate decision-making. Implementing KT strategies requires a defined plan. Identifying the needs, learning styles and preferred learning strategies of target audiences, coupled with evaluation, should be 
a piece of the overall concussion education puzzle to have an impact on enhancing knowledge and awareness.

\section{Author affiliations}

${ }^{1}$ The Florey Institute of Neuroscience and Mental Health, Heidelberg, Victoria, Australia

${ }^{2}$ Faculty of Kinesiology, Hotchkiss Brain Institute, University of Calgary, Calgary, Alberta, Canada

${ }^{3}$ Faculty of Medicine, Sport Injury Prevention Research Centre, Calgary, Alberta, Canada

${ }^{4}$ International Ice Hockey Federation, Switzerland

${ }^{5}$ IOC Medical Commission Games Group, Ottawa, Ontario, Canada

${ }^{6}$ Ottawa Sport Medicine Centre, Ottawa, Ontario, Canada

${ }^{7}$ Department of Neurosurgery, Boston University Medical Center, Boston,

Massachusetts, USA

${ }^{8}$ Center for the Study of Traumatic Encephalopathy, Boston University Medical Center, Boston, Massachusetts, USA

${ }^{9}$ Department of Neurology, University of Zurich, Zurich, Switzerland

${ }^{10}$ Schulthess Clinic Zurich, Zurich, Switzerland

${ }^{11}$ F-MARC (FIFA Medical Assessment and Research Center), Zurich, Switzerland

${ }^{12}$ Psychological and Neurobehavioral Associates, Inc., State College, Pennsylvania, USA

${ }^{13}$ University of Missouri-Kansas City, Kansas City, Missouri, USA

${ }^{14}$ Department of Orthopaedic Surgery, Oslo University Hospital and Faculty of Medicine, University of Oslo, Norway

${ }^{15}$ Oslo Sports Trauma Research Center, Norway

${ }^{16}$ International Olympic Committee (IOC), Lausanne, Switzerland

${ }^{17}$ Division of Neurosurgery, University of Toronto, Toronto, Canada

${ }^{18}$ Concussion Management Program Athletic Edge Sports Medicine, Toronto, Canada

${ }^{19}$ Michigan NeuroSport, Department of Neurology, University of Michigan, Ann Arbor, Michigan, USA

${ }^{20}$ International Rugby Board, Dublin, Ireland

${ }^{21}$ Department of Neurosurgery, Orthopaedic Surgery and Rehabilitation, Vanderbilt Sports Concussion Center, Vanderbilt University Medical Center, Nashville, Tennessee, USA

${ }^{22}$ Department of Clinical Neurosciences, Faculty of Medicine, University of Calgary Calgary, Alberta, Canada

${ }^{23}$ Department of Family Medicine, University of Calgary, Calgary, Alberta, Canada

${ }^{24}$ Sport Medicine Centre, Faculty of Kinesiology, University of Calgary, Calgary, Alberta,

Canada

${ }^{25}$ Department of Neurosurgery, Austin and Cabrini Hospitals \& The Florey Institute of

Neuroscience and Mental Health, Melbourne, Victoria, Australia

${ }^{26}$ Theodore S. Roberts Endowed Chair Department of Neurological Surgery University of Washington Seattle, WA, USA

${ }^{27}$ NFL Head, Neck and Spine Medical Committee

${ }^{28}$ Matthew Gfeller Sport-Related Traumatic Brain Injury Research Center, University of North Carolina, Chapel Hill, Chapel Hill, North Carolina, USA

${ }^{29}$ Clinical Professor Departments of Rehabilitation Medicine, Orthopaedics and Sports

Medicine and Neurological Surgery, University of Washington, USA

${ }^{30}$ Seattle Sports Concussion Program, Team Physician Seattle Seahawks and Seattle

Mariners, Seattle, Washington, USA

${ }^{31}$ Department of Psychiatry, University of British Columbia, Vancouver, British Columbia, Canada

${ }^{32}$ Weill Medical College of Cornell University, New York, New York, USA

${ }^{33}$ Burke Rehabilitation Hospital, White Plains, New York, USA

${ }^{34}$ New York State Athletic Commission. New York, New York, USA

${ }^{35}$ Department of Family Medicine, University of Ottawa, Ottawa, Canada

${ }^{36}$ Canadian National Men's Sledge Hockey Team, Canada

${ }^{37}$ National Football League Players Association (NFLPA) Mackey-White Traumatic Brain Injury Committee

${ }^{38}$ Brain Injury Research, Departments of Neurosurgery and Neurology, Medical College of Wisconsin, Wisconsin, USA

${ }^{39}$ Australian Centre for Research into Injury in Sports and its Prevention, Monash Injury Research Institute, Monash University, Australia

${ }^{40}$ Transport and Road Safety Research, Faculty of Science, the University of New South Wales, Australia

${ }^{41}$ McIntosh Consultancy and Research Pty Ltd. Sydney, Australia

${ }^{42}$ Perry Maddocks Trollope Lawyers, Melbourne, Australia

${ }^{43}$ The Florey Institute of Neuroscience and Mental Health, Melbourne Brain Centre, Austin Campus, Melbourne, Australia

${ }^{44}$ Centre For Health Exercise and Sports Medicine, Melbourne Physiotherapy Department, University of Melbourne, Melbourne, Australia

${ }^{45}$ Department of Pediatrics, McMaster University, Hamilton, Ontario, Canada

${ }^{46}$ David Braley Sport Medicine and Rehabilitation Centre, McMaster University, Hamilton, Ontario, Canada

${ }^{47}$ Princeton University, New Jersey, USA

${ }^{48}$ Robert Wood Johnson, University of Medicine and Dentistry of New Jersey (UMDNJ), USA

${ }^{49}$ Sport Injury Prevention Research Centre, Faculty of Kinesiology, University of Calgary,
Calgary, Alberta, Canada

${ }^{50}$ Toronto Western Hospital and University of Toronto, Canada

${ }^{51}$ Krembil Neuroscience Centre, Toronto, Canada

${ }^{52}$ ThinkFirst Canada

${ }^{53}$ Parachute, Canada

${ }^{54}$ British Horseracing Authority, London, UK

Competing interests See the supplementary online data for competing interests (http://dx.doi.org/10.1136/bjsports-2013-092313).

Provenance and peer review Commissioned; internally peer reviewed.

\section{REFERENCES}

1 Aubry M, Cantu R, Dvorak J, et al. Summary and agreement statement of the 1st International Symposium on Concussion in Sport, Vienna 2001. Clin J Sport Med 2002;12:6-11.

2 McCrory P, Johnston K, Meeuwisse W, et al. Summary and agreement statement of the 2nd International Conference on Concussion in Sport, Prague 2004. Br J Sports Med 2005:39:196-204.

3 McCrory P, Meeuwisse W, Johnston K, et al. Consensus statement on concussion in sport-the third international conference on concussion in sport held in Zurich, November 2008. Phys Sportsmed 2009;37:141-59.

4 Maddocks D, Dicker G. An objective measure of recovery from concussion in Australian rules footballers. Sport Health 1989;7(Suppl):6-7.

5 Maddocks DL, Dicker GD, Saling MM. The assessment of orientation following concussion in athletes. Clin J Sport Med 1995;5:32-5.

6 McCrea M. Standardized mental status assessment of sports concussion. Clin J Sport Med 2001:11:176-81.

7 McCrea M, Kelly J, Randolph C, et al. Standardised assessment of concussion (SAC): on site mental status evaluation of the athlete. J Head Trauma Rehab 1998;13:27-36

8 McCrea M, Randolph C, Kelly J. The Standardized Assessment of Concussion (SAC): manual for administration, scoring and interpretation. 2nd edn. Waukesha, WI, 2000.

9 McCrea M, Kelly JP, Kluge J, et al. Standardized assessment of concussion in football players. Neurology 1997:48:586-8.

10 Chen J, Johnston K, Collie A, et al. A validation of the Post Concussion Symptom Scale in the assessment of complex concussion using cognitive testing and functional MRI. J Neurol Neurosurg Psych 2007;78:1231-8.

11 Chen J, Johnston $\mathrm{K}$, Frey $\mathrm{S}$, et al. Functional abnormalities in symptomatic concussed athletes: an fMRI study. Neuroimage 2004;22:68-82.

12 Chen JK, Johnston KM, Collie A, et al. (14) Association between symptom severity, CogSport tests results, and functional MRI activation in symptomatic concussed athletes. Clin J Sport Med 2004;14:379.

13 Chen JK, Johnston KM, Collie A, et al. Behavioural and functional imaging outcomes in symptomatic concussed athletes measured with cogsport and functional MRI. BJ Sport Med 2004;38:659.

14 Ptito A, Chen JK, Johnston KM. Contributions of functional magnetic resonance imaging (fMRI) to sport concussion evaluation. NeuroRehabilitation 2007:22:217-27.

15 Guskiewicz K. Postural stability assessment following concussion. Clin J Sport Med 2001:11:182-90.

16 Guskiewicz KM. Assessment of postural stability following sport-related concussion. Curr Sports Med Rep 2003:2:24-30.

17 Guskiewicz KM, Ross SE, Marshall SW. Postural stability and neuropsychological deficits after concussion in collegiate athletes. J Athl Train 2001;36:263-73.

18 Cavanaugh JT, Guskiewicz KM, Giuliani C, et al. Detecting altered postural control after cerebral concussion in athletes with normal postural stability. $\mathrm{Br} J$ Sports Med 2005;39:805-11.

19 Cavanaugh JT, Guskiewicz KM, Giuliani C, et al. Recovery of postural control after cerebral concussion: new insights using approximate entropy. J Athl Train 2006;41:305-13.

20 Cavanaugh JT, Guskiewicz KM, Stergiou N. A nonlinear dynamic approach for evaluating postural control: new directions for the management of sport-related cerebral concussion. Sports Med (Auckland, NZ) 2005;35:935-50.

21 Fox ZG, Mihalik JP, Blackburn JT, et al. Return of postural control to baseline after anaerobic and aerobic exercise protocols. J Ath/ Train 2008:43:456-63.

22 Kristman VL, Tator $\mathrm{CH}$, Kreiger N, et al. Does the apolipoprotein epsilon 4 allele predispose varsity athletes to concussion? A prospective cohort study. Clin J Sport Med 2008:18:322-8.

23 Terrell TR, Bostick RM, Abramson R, et al. APOE, APOE promoter, and Tau genotypes and risk for concussion in college athletes. Clin J Sport Med 2008;18:10-17

24 Vagnozzi R, Tavazzi B, Signoretti S, et al. Temporal window of metabolic brain vulnerability to concussions: mitochondrial-related impairment-part I. Neurosurgery 2007;61:379-88; discussion 88-9.

25 Hang CH, Chen G, Shi JX, et al. Cortical expression of nuclear factor kappaB after human brain contusion. Brain Res 2006;1109:14-21.. 
26 Peng RY, Gao YB, Xiao XY, et al. [Study on the expressions of basic fibroblast growth factor and nervous growth factor genes in rat cerebral concussion]. Zhongguo Wei Zhong Bing Ji Jiu Yi Xue 2003;15:213-16.

27 Yunoki M, Kawauchi M, Ukita N, et al. Effects of lecithinized SOD on sequential change in SOD activity after cerebral contusion in rats. Acta Neurochir Supp/ 1998;71:142-5.

28 Hinkle DA, Baldwin SA, Scheff SW, et al. GFAP and S100beta expression in the cortex and hippocampus in response to mild cortical contusion. J Neurotrauma 1997;14:729-38.

29 Holmin S, Schalling M, Hojeberg B, et al. Delayed cytokine expression in rat brain following experimental contusion. J Neurosurg 1997;86:493-504.

30 Sandberg Nordqvist AC, von Holst $\mathrm{H}$, Holmin S, et al. Increase of insulin-like growth factor (IGF)-1, IGF binding protein-2 and -4 mRNAs following cerebral contusion. Brain Res Mol Brain Res 1996:38:285-93.

31 Fukuhara $\mathrm{T}$, Nishio $\mathrm{S}$, Ono $\mathrm{Y}$, et al. Induction of $\mathrm{Cu}, \mathrm{Zn}$-superoxide dismutase after cortical contusion injury during hypothermia. Brain Res 1994;657:333-6.

32 Begaz T, Kyriacou DN, Segal J, et al. Serum biochemical markers for post-concussion syndrome in patients with mild traumatic brain injury. J Neurotrauma 2006;23:1201-10.

33 de Boussard CN, Lundin A, Karlstedt D, et al. S100 and cognitive impairment after mild traumatic brain injury. J Rehabil Med 2005;37:53-7.

34 Lima DP, Simao Filho C, Abib Sde C, et al. Quality of life and neuropsychological changes in mild head trauma. Late analysis and correlation with S100B protein and cranial CT scan performed at hospital admission. Injury 2008:39:604-11.

35 Ma M, Lindsell CJ, Rosenberry CM, et al. Serum cleaved tau does not predict postconcussion syndrome after mild traumatic brain injury. Am J Emerg Med 2008;26:763-8

36 Stalnacke BM, Tegner Y, Sojka P. Playing ice hockey and basketball increases serum levels of S-100B in elite players: a pilot study. Clin I Sport Med 2003;13:292-302

37 Stalnacke BM, Tegner Y, Sojka P. Playing soccer increases serum concentrations of the biochemical markers of brain damage S-100B and neuron-specific enolase in elite players: a pilot study. Brain Inj 2004:18:899-909.

38 Townend $W$, Ingebrigtsen $T$. Head injury outcome prediction: a role for protein S-100B? Injury 2006:37:1098-108.

39 Boutin D, Lassonde M, Robert M, et al. Neurophysiological assessment prior to and following sports-related concussion during childhood: a case study. Neurocase 2008:14:239-48

40 De Beaumont L, Brisson B, Lassonde $\mathrm{M}$, et al. Long-term electrophysiological changes in athletes with a history of multiple concussions. Brain Inj 2007:21:631-44.

41 De Beaumont $\mathrm{L}$, Lassonde $\mathrm{M}$, Leclerc $\mathrm{S}$, et al. Long-term and cumulative effects of sports concussion on motor cortex inhibition. Neurosurgery 2007;61:329-36; discussion 36-7.

42 Gaetz M, Weinberg H. Electrophysiological indices of persistent post-concussion symptoms. Brain Inj 2000;14:815-32.

43 Gosselin N, Theriault M, Leclerc S, et al. Neurophysiological anomalies in symptomatic and asymptomatic concussed athletes. Neurosurgery 2006:58:1151-61; discussion -61.

44 Lavoie ME, Dupuis F, Johnston KM, et al. Visual p300 effects beyond symptoms in concussed college athletes. J Clin Exp Neuropsychol 2004;26:55-73.

45 Rousseff RT, Tzvetanov P, Atanassova PA, et al. Correlation between cognitive P300 changes and the grade of closed head injury. Electromyogr Clin Neurophysiol 2006:46:275-7.

46 Collie A, Darby D, Maruff P. Computerised cognitive assessment of athletes with sports related head injury. Br J Sports Med 2001:35:297-302.

47 Collie A, Maruff P. Computerised neuropsychological testing. Br I Sports Med 2003;37:2-3.

48 Collie A, Maruff P, McStephen M, et al. Psychometric issues associated with computerised neuropsychological assessment of concussed athletes. $\mathrm{Br} / \mathrm{Sports}$ Med 2003;37:556-9.

49 Collins MW, Grindel SH, Lovell MR, et al. Relationship between concussion and neuropsychological performance in college football players [see comments]. JAMA 1999;282:964-70

50 Lovell MR. The relevance of neuropsychologic testing for sports-related head injuries. Curr Sports Med Rep 2002;1:7-11.

51 Lovell MR, Collins MW. Neuropsychological assessment of the college football player. J Head Trauma Rehabil 1998;13:9-26.

52 Bleiberg J, Cernich AN, Cameron K, et al Duration of cognitive impairment after sports concussion. Neurosurgery 2004;54:1073-8; discussion 8-80.

53 Bleiberg J, Warden D. Duration of cognitive impairment after sports concussion. Neurosurgery 2005:56:E1166.

54 Broglio SP, Macciocchi SN, Ferrara MS. Neurocognitive performance of concussed athletes when symptom free. J Athl Train 2007:42:504-8.

55 Broglio SP, Macciocchi SN, Ferrara MS. Sensitivity of the concussion assessment battery. Neurosurgery 2007:60:1050-7; discussion 7-8.
56 Gioia G, Janusz J, Gilstein K, et al. Neueopsychological management of consussion in children and adolescents: effects of age and gender on ImPact (abstract). Br J Sp Med 2004:38:657.

57 McCrory P, Collie A, Anderson V, et al. Can we manage sport related concussion in children the same as in adults? Br J Sports Med 2004:38:516-19.

58 Johnston K, Bloom G, Ramsay J, et al. Current concepts in concussion rehabilitation. Curr Sports Med Rep 2004;3:316-23.

59 Guskiewicz KM, McCrea M, Marshall SW, et al. Cumulative effects associated with recurrent concussion in collegiate football players. JAMA 2003;290:2549-55.

60 Lovell M, Collins M, Bradley J. Return to play following sports-related concussion. Clin Sports Med 2004;23:421-41, ix.

61 Collins M, Field M, Lovell M, et al. Relationship between postconcussion headache and neuropsychological test performance in high school athletes. Am J Sports Med 2003:31:168-73.

62 Collins M, Grindel S, Lovell M, et al. Relationship between concussion and neuropsychological performance in college football players. J Am Med Assoc 1999;282:964-70.

63 Collins MW, Lovell MR, Iverson $\mathrm{GL}$, et al. Cumulative effects of concussion in high school athletes. Neurosurgery 2002:51:1175-9; discussion 80-1.

64 McCrea M, Guskiewicz KM, Marshall SW, et al. Acute effects and recovery time following concussion in collegiate football players. JAMA 2003:290:2556-63.

65 McCrea M, Hammeke T, Olsen G, et al. Unreported concussion in high school football players: implications for prevention. Clin I Sport Med 2004;14:13-17.

66 Bloom G, Horton A, McCrory P, et al. Sport psychology and concussion: new impacts to explore. Br J Sports Med 2004;38:519-21.

67 Weiss MR, Gill DL. What goes around comes around: re-emerging themes in sport and exercise psychology. Res Q Exerc Sport 2005;76:S71-87.

68 McCrory P. Should we treat concussion pharmacologically? The need for evidence based pharmacological treatment for the concussed athlete. Br I Sports Med 2002:36:3-5.

69 McCrory P. Preparticipation assessment for head injury. Clin I Sport Med 2004:14:139-44.

70 Johnston KM, Lassonde M, Ptito A. A contemporary neurosurgical approach to sport-related head injury: the McGill concussion protocol. J Am Coll Surg 2001;192:515-24

71 Delaney J, Lacroix V, Leclerc S, et al. Concussions during the 1997 Canadian Football League Season. Clin J Sport Med 2000;10:9-14.

72 Delaney J, Lacroix V, Leclerc $\mathrm{S}$, et al. Concussions among university football and soccer players. Clin I Sport Med 2002;12:331-8.

73 Gessel LM, Fields SK, Collins CL, et al. Concussions among United States high school and collegiate athletes. J Athl Train 2007:42:495-503.

74 Dvorak J, Junge A, Fuller C, et al. Medical issues in women's football. Br J Sports Med 2007:41(Suppl 1):i1.

75 Dvorak J, McCrory P, Kirkendall DT. Head injuries in the female football player: incidence, mechanisms, risk factors and management. Br I Sports Med 2007:41 (Suppl 1):i44-6.

76 Jennett B, Bond M. Assessment of outcome after severe brain damage: a practical scale. Lancet 1975;1:480-4.

77 Leninger B, Gramling S, Farrell A, et al. Neuropsychological deficits in symptomatic minor head injury patients after concussion and mild concussion. J Neurol Neurosurg Psych 1990;53:293-6.

78 Lovell $M$, Iverson $\mathrm{G}$, Collins $\mathrm{M}$, et al. Does loss of consciousness predict neuropsychological decrements after concussion. Clin I Sp Med 1999;9:193-9.

79 McCrea M, Kelly J, Randolph C, et al. Immediate neurocognitive effects of concussion. Neurosurgery 2002;50:1032-42.

80 Cantu RC. Posttraumatic retrograde and anterograde amnesia: pathophysiology and implications in grading and safe return to play. J Athl Train 2001;36:244-8

81 Lovell MR, Collins MW, Iverson GL, et al. Recovery from mild concussion in high school atheltes. J Neurosurg 2003;98:296-301.

82 McCrory PR, Ariens T, Berkovic SF. The nature and duration of acute concussive symptoms in Australian football. Clin I Sport Med 2000;10:235-8.

83 Yarnell P, Lynch S. The 'ding': amnestic state in football trauma. Neurology 1973:23:196-7.

84 Yarnell PR, Lynch S. Retrograde memory immediately after concussion. Lancet 1970;1:863-4

85 McCrory PR, Berkovic SF. Video analysis of acute motor and convulsive manifestations in sport-related concussion. Neurology 2000;54:1488-91.

86 McCrory PR, Bladin PF, Berkovic SF. Retrospective study of concussive convulsions in elite Australian rules and rugby league footballers: phenomenology, aetiology, and outcome. BMJ 1997:314:171-4.

87 Fleminger $S$. Long-term psychiatric disorders after traumatic brain injury. Eur $J$ Anaesthesiol Suppl 2008:42:123-30.

88 Chen JK, Johnston KM, Petrides M, et al. Neural substrates of symptoms of depression following concussion in male athletes with persisting postconcussion symptoms. Arch Gen Psychiatry 2008;65:81-9.

89 Bryant RA. Disentangling mild traumatic brain injury and stress reactions. N Engl J Med 2008:358:525-7. 
90 Vanderploeg RD, Curtiss G, Luis CA, et al. Long-term morbidities following self-reported mild traumatic brain injury. J Clin Exp Neuropsychol 2007:29:585-98.

91 Guskiewicz KM, Marshall SW, Bailes J, et al. Recurrent concussion and risk of depression in retired professional football players. Med Sci Sports Exerc 2007:39:903-9.

92 Kashluba S, Casey JE, Paniak C. Evaluating the utility of ICD-10 diagnostic criteria for postconcussion syndrome following mild traumatic brain injury. J Int Neuropsychol Soc 2006;12:111-18.

93 Iverson GL. Misdiagnosis of the persistent postconcussion syndrome in patients with depression. Arch Clin Neuropsychol 2006;21:303-10.

94 Chamelian L, Feinstein A. The effect of major depression on subjective and objective cognitive deficits in mild to moderate traumatic brain injury. J Neuropsychiatry Clin Neurosci 2006;18:33-8.

95 Mooney G, Speed J, Sheppard S. Factors related to recovery after mild traumatic brain injury. Brain Inj 2005;19:975-87.

96 Broshek DK, Freeman JR. Psychiatric and neuropsychological issues in sport medicine. Clin Sports Med 2005;24:663-79, x.

97 Pellman EJ. Background on the National Football League's research on concussion in professional football. Neurosurgery 2003;53:797-8.

98 Purcell L, Carson J. Sport-related concussion in pediatric athletes. Clin Pediatr (Phila) 2008;47:106-13

99 Lee LK. Controversies in the sequelae of pediatric mild traumatic brain injury. Pediatr Emerg Care 2007;23:580-3; quiz 4-6.

100 Schnadower D, Vazquez $\mathrm{H}$, Lee J, et al. Controversies in the evaluation and management of minor blunt head trauma in children. Curr Opin Pediatr 2007; 19:258-64.

101 Wozniak JR, Krach L, Ward E, et al. Neurocognitive and neuroimaging correlates of pediatric traumatic brain injury: a diffusion tensor imaging (DTI) study. Arch Clin Neuropsychol 2007;22:555-68

102 Hayden MG, Jandial R, Duenas HA, et al. Pediatric concussions in sports; a simple and rapid assessment tool for concussive injury in children and adults. Childs Nerv Syst 2007;23:431-5.

103 Lee MA. Adolescent concussions-management recommendations: a practical approach. Conn Med 2006;70:377-80.

104 Kirkwood MW, Yeates KO, Wilson PE. Pediatric sport-related concussion: a review of the clinical management of an oft-neglected population. Pediatrics 2006;117:1359-71.

105 Guskiewicz KM, Marshall SW, Bailes J, et al. Association between recurrent concussion and late-life cognitive impairment in retired professional football players. Neurosurgery 2005;57:719-26; discussion -26.

106 Nandoe RD, Scheltens P, Eikelenboom P. Head trauma and Alzheimer's disease. J Alzheimers Dis 2002;4:303-8.

107 Stern MB. Head trauma as a risk factor for Parkinson's disease. Mov Disord 1991:6:95-7.

108 Omalu BI, DeKosky ST, Hamilton RL, et al. Chronic traumatic encephalopathy in a national football league player: part II. Neurosurgery 2006;59:1086-92; discussion 92-3.

109 Omalu BI, DeKosky ST, Minster RL, et al. Chronic traumatic encephalopathy in a National Football League player. Neurosurgery 2005;57:128-34; discussion -34.

110 McKee AC, Cantu RC, Nowinski CJ, et al. Chronic traumatic encephalopathy in athletes: progressive tauopathy after repetitive head injury. J Neuropathol Exp Neurol 2009;68:709-35

111 McKee AC, Gavett BE, Stern RA, et al. TDP-43 Proteinopathy and Motor Neuron Disease in Chronic Traumatic Encephalopathy. J Neuropathol Exp Neurol 2010:69:918-29.

112 McKee AC, Stein TD, Nowinski CJ, et al. The spectrum of disease in chronic traumatic encephalopathy. Brain 2013;136:43-64.

113 McCrory P. Sports concussion and the risk of chronic neurological impairment. Clin J Sport Med 2011;21:6-12.

114 McCrory P. Future advances and areas of future focus in the treatment of sport-related concussion. Clin Sports Med 2011;30:201-8, xi-ii.

115 Hagel BE, Pless IB, Goulet $C$, et al. Effectiveness of helmets in skiers and snowboarders: case-control and case crossover study. BMJ (Clin Res ed) 2005:330:281.

$116 \mathrm{McC}$ rory P. The role of helmets in skiing and snowboarding. Br J Sports Med 2002;36:314

117 Mueller BA, Cummings P, Rivara FP, et al. Injuries of the head, face, and neck in relation to ski helmet use. Epidemiology 2008;19:270-6.

118 Sulheim S, Holme I, Ekeland A, et al. Helmet use and risk of head injuries in alpine skiers and snowboarders. JAMA 2006;295:919-24.

119 Delaney JS, Al-Kashmiri A, Drummond R, et al. The effect of protective headgear on head injuries and concussions in adolescent football (soccer) players. $\mathrm{Br} \mathrm{J}$ Sports Med 2008;42:110-15; discussion 5

120 Viano DC, Pellman EJ, Withnall C, et al. Concussion in professional football: performance of newer helmets in reconstructed game impacts-part 13. Neurosurgery 2006;59:591-606; discussion 591-606.
121 Finch C, Braham R, McIntosh A, et al. Should football players wear custom fitted mouthguards? Results from a group randomised controlled trial. Inj Prev 2005;11:242-6.

122 Mclntosh A, McCrory P. The dynamics of concussive head impacts in rugby and Australian rules football. Med Sci Sports Exerc 2000;32:1980-5.

123 McIntosh A, McCrory P. Impact energy attenuation performance of football headgear. Br J Sports Med 2000;34:337-42.

124 Mclntosh A, McCrory P. Effectiveness of headgear in a pilot study of under 15 rugby union football. Br J Sports Med 2001;35:167-70.

125 Mclntosh A, McCrory P, Finch C, et al. Rugby Headgear Study. Sydney: School of Safety Science, The University of New South Wales, May 2005.

126 Finch C, Newstead S, Cameron M, et al. Head injury reductions in Victoria two years after the introduction of mandatory bicycle helmet use. Melbourne: Monash University Accident Research Centre, 1993 July, Report No.: 51.

127 Curnow WJ. Bicycle helmets and public health in Australia. Health Promot J Austr 2008:19:10-15.

128 Hewson PJ. Cycle helmets and road casualties in the UK. Traffic Inj Prev 2005:6:127-34

129 Davidson JA. Epidemiology and outcome of bicycle injuries presenting to an emergency department in the United Kingdom. Eur J Emerg Med 2005;12:24-9.

130 Hansen KS, Engesaeter LB, Viste A. Protective effect of different types of bicycle helmets. Traffic Inj Prev 2003;4:285-90.

131 Andersen T, Arnason A, Engebretsen L, et al. Mechanism of head injuries in elite football. Br J Sports Med 2004;38:690-6.

132 Hagel B, Meewisse W. Editorial: risk compensation: a "side effect" of sport injury prevention? Clin J Sp Med 2004;14:193-6.

133 Finch C, Mcintosh AS, McCrory P, et al. A pilot study of the attitudes of Australian Rules footballers towards protective headgear. I Sci Med Sport 2003:6:505-11.

134 Finch CF, Mclntosh AS, McCrory P. What do under 15-year-old schoolboy rugby union players think about protective headgear? BrJ Sports Med 2001;35:89-94.

135 Finch C, Mcintosh AS, McCrory P. What is the evidence base for the use of protective headgear and mouthguards in Australian football. Sport Health 2000;18:35-8

136 Reece RM, Sege R. Childhood head injuries: accidental or inflicted? Arch Pediatr Adolesc Med 2000;154:11-15.

137 Shaw NH. Bodychecking in hockey. CMAJ 2004;170:15-16; author reply 6, 8 .

138 Denke NJ. Brain injury in sports. J Emerg Nurs 2008;34:363-4.

139 Gianotti S, Hume PA. Concussion sideline management intervention for rugby union leads to reduced concussion claims. NeuroRehabilitation 2007;22:181-9.

140 Guilmette TJ, Malia LA, McQuiggan MD. Concussion understanding and management among New England high school football coaches. Brain Inj 2007:21:1039-47.

141 Hootman JM, Dick R, Agel J. Epidemiology of collegiate injuries for 15 sports: summary and recommendations for injury prevention initiatives. J Ath/ Train 2007:42:311-19

142 Valovich McLeod TC, Schwartz C, Bay RC. Sport-related concussion misunderstandings among youth coaches. Clin J Sport Med 2007;17:140-2.

143 Sye G, Sullivan SJ, McCrory P. High school rugby players' understanding of concussion and return to play guidelines. Br J Sports Med 2006:40:1003-5.

144 Theye F, Mueller KA. "Heads up": concussions in high school sports. Clin Med Res 2004:2:165-71.

145 Kashluba S, Paniak C, Blake T, et al. A longitudinal, controlled study of patient complaints following treated mild traumatic brain injury. Arch Clin Neuropsychol 2004;19:805-16.

146 Gabbe B, Finch CF, Wajswelner $\mathrm{H}$, et al. Does community-level Australian football support injury prevention research? J Sci Med Sport 2003;6:231-6.

147 Kaut KP, DePompei R, Kerr J, et al. Reports of head injury and symptom knowledge among college athletes: implications for assessment and educational intervention. Clin J Sport Med 2003;13:213-21.

148 Davidhizar R, Cramer C. The best thing about the hospitalization was that the nurses kept me well informed" issues and strategies of client education. Accid Emerg Nurs 2002:10:149-54.

149 McCrory P. What advice should we give to athletes postconcussion? Br J Sports Med 2002:36:316-18.

150 Bazarian JJ, Veenema T, Brayer AF, et al. Knowledge of concussion guidelines among practitioners caring for children. Clin Pediatr (Phila) 2001;40:207-12.

151 Guskiewicz KM, Weaver NL, Padua DA Jr, et al. Epidemiology of concussion in collegiate and high school football players. Am J Sports Med 2000;28:643-50.

152 McCrea M, Guskiewicz KM, Marshall SW, et al. Acute effects and recovery time following concussion in collegiate football players: the NCAA Concussion Study. JAMA 2003;290:2556-63.

153 Macciocchi SN, Barth JT, Alves W, et al. Neuropsychological functioning and recovery after mild head injury in collegiate athletes. Neurosurgery 1996:39:510-14. 
154 Meehan WP III, d'Hemecourt P, Comstock RD. High school concussions in the 2008-2009 academic year: mechanism, symptoms, and management. Am I Sports Med 2010;38:2405-9.
155 Eckner JT, Kutcher JS, Richardson JK. Between-seasons test-retest reliability of clinically measured reaction time in National Collegiate Athletic Association Division I athletes. J Athl Train 2011:46:409-14.

156 Eckner JT, Richardson JK, Kim H, et al. A novel clinical test of recognition reaction time in healthy adults. Psychol Assess 2012;24:249-54. $\underline{\underline{c}}$

$c$

$\frac{\infty}{8}$

ले

3

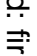

के

등

के

$\stackrel{\mathbb{1}}{\circ}$

क

$\overrightarrow{0}$

$\vec{\omega}$

م

$\frac{\partial}{0}$

우

N

$\frac{1}{\omega}$

8

$\frac{\omega}{\omega}$

욱

ב

3

옹

옹

प̆

\)

응

$\stackrel{\mathbb{Q}}{\square}$

$\overrightarrow{\overrightarrow{0}}$

כ

함 